\title{
Iridium concentration and noble gas composition of Cretaceous-Tertiary boundary clay from Stevns Klint, Denmark
}

\author{
Takahito Osawa, ${ }^{1 *}$ Yuichi Hatsukawa,,${ }^{1}$ Keisuke Nagao,${ }^{2}$ Mitsuo Koizumi,${ }^{3}$ Masumi Oshima, ${ }^{3}$ \\ Yosuke Toh, ${ }^{3}$ Atsushi Kimura ${ }^{3}$ and KAZUYOShi FurutakA ${ }^{3}$

\begin{abstract}
${ }^{1}$ Neutron Imaging and Activation Analysis Group, Quantum Beam Science Directorate, Japan Atomic Energy Agency (JAEA), Tokai-mura, Naka-gun, Ibaraki 319-1195, Japan

${ }^{2}$ Laboratory for Earthquake Chemistry, Graduate School of Science, The University of Tokyo, Hongo, Tokyo 113-0033, Japan

${ }^{3}$ Innovative Nuclear Science Research Group, Nuclear Science and Engineering Directorate, Japan Atomic Energy Agency (JAEA), Tokai-mura, Naka-gun, Ibaraki 319-1195, Japan
\end{abstract}

(Received January 12, 2009; Accepted May 13, 2009)

\begin{abstract}
The Cretaceous-Tertiary (K-T) boundary about 65 million years ago records a mass extinction event caused by a bolide impact. K-T boundary clay collected from Stevns Klint, Denmark was investigated in this work. Iridium concentrations of eight clays across the K-T boundary were determined using a multiple gamma-ray analysis system after neutron activation. Anomalously high Ir concentrations were detected in five marl samples, with the highest concentration being $29.9 \mathrm{ppb}$. Four samples were analyzed for all noble gases. No extraterrestrial Ar, Kr, and Xe were discovered in any of the samples, although most of the ${ }^{3} \mathrm{He}$ which was detected was extraterrestrial. Solar-like Ne was observed only in the sample SK4, which had an Ir concentration of $14.3 \mathrm{ppb}$, indicating the presence of micrometeorites. The solar-like Ne clearly did not originate from an asteroid/comet associated with the bolide impact, as that asteroid is thought to have been extremely large. Also, because there was no sign of a high accretion rate of micrometeorites at the boundary it could not be ascertained whether the solar-like Ne was related to a catastrophic event that led to the extinction of the dinosaurs.
\end{abstract}

Keywords: K-T boundary, iridium, noble gas

\section{INTRODUCTION}

It is well known that the concentration of Ir in Cretaceous-Tertiary $(\mathrm{K}-\mathrm{T})$ boundary clay is anomalously high, over 30 ppb (Alvarez et al., 1980; Kyte et al., 1980; Kastner et al., 1984). The Ir-anomaly clearly indicates that a bolide impact occurred about 65 million years ago, corresponding to the Chicxulub crater buried beneath the Yucatán Peninsula in Mexico (e.g., Sharpton et al., 1992).

Although noble gas is one of the most sensitive indicators for extraterrestrial material, no extraterrestrial noble gases associated with a bolide impact have been detected in the K-T boundary layer (Eugster et al., 1985; Wolbach et al., 1985; Lewis and Wolbach, 1986; Amari et al., 1988; Takaoka and Miura, 1989). A study by Eugster et al. (1985) mainly attempted to find if there was any enrichment of extraterrestrial $\mathrm{He}$ in residue treated with $\mathrm{HCl}$ and HF. Although they did discover excessive amounts of ${ }^{3} \mathrm{He}$ in some Stevns Klint residue, they attributed it to the outgassing of primordial ${ }^{3} \mathrm{He}$ from the man-

*Corresponding author (e-mail: osawa.takahito@jaea.go.jp) Copyright @ 2009 by The Geochemical Society of Japan. tle of the earth or ${ }^{6} \mathrm{Li}(n, \alpha \beta)^{3} \mathrm{He}$ reactions. Lewis and Wolbach (1986) attempted to detect Carbonaceous Chondrite Fission (CCF)-Xe in samples from Stevns Klint and Woodside Creek in New Zealand. Excess fission ${ }^{136} \mathrm{Xe}$ was discovered in all the samples after being treated with acid, but most or all of that excess was considered to have resulted from the $n$-induced fission of U. Amari et al. (1988) measured the ${ }^{3} \mathrm{He} /{ }^{4} \mathrm{He}$ ratios of clay from Hokkaido in Japan. However, they could only determine the upper limit of the ${ }^{3} \mathrm{He} /{ }^{4} \mathrm{He}$ ratio $\left(<6.2 \times 10^{-6}\right)$, which is not a positive sign of it being extraterrestrial He.

Takaoka and Miura (1989) also measured K-T boundary clay from Stevns Klint and discovered spallogenic $\mathrm{He}$ and $\mathrm{Ne}$ in a fraction treated with $\mathrm{HCl} / \mathrm{HF}$. However, although this is a result positively indicating the presence of extraterrestrial noble gases, it is not demonstrative proof, because spallogenic $\mathrm{He}$ and $\mathrm{Ne}$ have also been reported in summit lava on Maui (Marti and Craig, 1987). In addition, the concentration of spallogenic $\mathrm{He}$ and $\mathrm{Ne}$ from a massive object that fell to the earth 65 million years ago (10 $\pm 4 \mathrm{~km}$ in diameter, Alvarez et al., 1980) would be very low.

The lack of extraterrestrial noble gases associated with a bolide impact in the $\mathrm{K}-\mathrm{T}$ boundary can be explained in 
Table 1. Ir concentration of fish clay

\begin{tabular}{lcrrrrl}
\hline Sample & Weight $(\mathrm{mg})$ & Detection time $(\mathrm{sec})$ & \multicolumn{2}{c}{ Ir } & \multirow{2}{*}{ Noble gas measurement } & Color \\
\cline { 4 - 5 } & & & $\mathrm{ppb}$ & $\mathrm{error}(\%)$ & \\
\hline SK1a & 62.79 & 6157 & 24.7 & 2.0 & $\sqrt{ }$ & gray \\
SK1b & 59.23 & 6545 & 5.3 & 4.6 & $\sqrt{ }$ & light gray \\
SK2 & 74.85 & 4594 & 27.8 & 2.4 & $\sqrt{ }$ & brown \\
SK3 & 62.66 & 52301 & 2.2 & 2.5 & $\sqrt{ }$ & light gray \\
SK4 & 76.70 & 5386 & 14.3 & 2.6 & gray \\
SK5 & 80.93 & 4931 & 22.5 & 2.1 & gray \\
SK6 & 60.02 & 5237 & 4.9 & 5.1 & light gray \\
SK7 & 62.50 & 6170 & 29.9 & 2.2 & brown \\
JP1* & 74.29 & 53840 & 3.0 & 2.2 & \\
\hline
\end{tabular}

*Geochemical reference sample (Horoman peridotite).

four ways. The first is that primordial noble gas components trapped in a huge meteorite were completely degassed during projection so that no extraterrestrial noble gases remained in the K-T boundary clay. The second is that extraterrestrial noble gases were left there but their concentrations are very low. The third is that the noble gases were lost in the acid treatment. The fourth is that the $\mathrm{K}-\mathrm{T}$ mass extinction and $\mathrm{Ir}$ anomaly have no extraterrestrial cause.

Even if one of these hypotheses is correct, previous studies clearly show that the concentration of extraterrestrial noble gas is low or that carrier phases of noble gases are easily decomposed by acids. The latter finding contradicts the already-known property of chondrites that the trapped primordial noble gas component of chondrites is concentrated in an acid-resistant phase (e.g., Lewis et al., 1975). However, the type of the impact asteroid cannot be completely identified, and the influence of diagenesis of the phase is not understood well.

In our study, the noble gas composition of $\mathrm{K}-\mathrm{T}$ boundary clays without acid treatment was determined by a highly refined noble gas analytical system, and iridium concentrations of the clays were determined using a multiple gamma-ray analysis system.

\section{SAMPLE}

The K-T boundary clay tested in the present study was collected by Nagao K. from Stevns Klint in Denmark in 1992. The specimens were removed from a thin layer of marl, which is known as fish clay. Danish fish clay was subdivided into 4 beds from bed II at the bottom to bed $\mathrm{V}$ at the top (Christensen et al., 1973). Under bed II was Maastrichtian white chalk (bed I) and over bed V was Cerithium limestone (bed VI). The samples used in this report were taken from beds II, III, or IV. Bed III was a dark brown color due to weathering of the pyrite con- cretion. The samples were stored at room temperature and were not dried. The samples are listed in Table 1. Four of eight samples were subjected to noble gas analysis.

\section{Experimental Procedures}

\section{Noble gas measurement}

The samples were not chemically or physically separated to determine their bulk noble gas composition. The samples were preheated at $150^{\circ} \mathrm{C}$ for a day in a high vacuum to remove any contaminating atmospheric gases adsorbed to their surfaces. Noble gases were extracted by heating in a tantalum oven, in which the samples were pyrolysed at 900 to $1800^{\circ} \mathrm{C}$. All the temperature steps were held for 15 minutes. The extracted gases were then purified using three Ti-Zr getters (getters 1,2, and 3), and $\mathrm{Ar}, \mathrm{Kr}$, and $\mathrm{Xe}$ were trapped in a liquid-nitrogen-cooled charcoal trap. Since sedimentary material generally has a large variety of volatile species which can cause problems in the purification process, the released gas was purified for 30 minutes using getter 1 . Ne was trapped in a cryogenically cooled trap at $15 \mathrm{~K}$, He was introduced into the mass spectrometer, and the isotopic composition was then analyzed. Ne was released at $45 \mathrm{~K}$ from the cryogenically cooled trap and measured using the spectrometer. After Ar, Kr, and Xe were released from the charcoal trap, the $\mathrm{Kr}$ and $\mathrm{Xe}$ were captured in the cryogenic trap at $100 \mathrm{~K}$ and the Ar was then measured. $\mathrm{Kr}$ and Xe were released at $135 \mathrm{~K}$ and $200 \mathrm{~K}$, respectively, from the trap and measured. The noble gas isotopes were analyzed using a highly sensitive mass spectrometer (modified VG-5400/MS-III). A Daly collector was used to measure the light noble gases ( $\mathrm{He}, \mathrm{Ne}$ and $\mathrm{Ar}$ ) while the $\mathrm{Kr}$ and $\mathrm{Xe}$ isotopes were measured using a secondary electron multiplier with an ion counting system. The sensitivities to all the noble gases and mass discrimination effects were calibrated by measuring atmospheric noble 
Table 2. Concentration and isotopic ratio of helium and neon

\begin{tabular}{|c|c|c|c|c|c|c|c|c|}
\hline Sample & $\begin{array}{l}\text { Weight } \\
(\mathrm{g})\end{array}$ & $\begin{array}{c}{ }^{4} \mathrm{He} \\
\left(10^{-9} \mathrm{~cm}^{3} \mathrm{STP} / \mathrm{g}\right)\end{array}$ & $\begin{array}{c}{ }^{3} \mathrm{He} \\
\left(10^{-15} \mathrm{~cm}^{3} \mathrm{STP} / \mathrm{g}\right)\end{array}$ & $\begin{array}{c}{ }^{3} \mathrm{He} /{ }^{4} \mathrm{He} \\
\left(10^{-6}\right)\end{array}$ & $\begin{array}{c}{ }^{-12} \mathrm{Ne} \\
\left(10^{-12} \mathrm{~cm}^{3} \mathrm{STP} / \mathrm{g}\right)\end{array}$ & ${ }^{20} \mathrm{Ne} /{ }^{22} \mathrm{Ne}$ & ${ }^{21} \mathrm{Ne} /{ }^{22} \mathrm{Ne}$ & ${ }^{4} \mathrm{He} /{ }^{20} \mathrm{Ne}$ \\
\hline SK1a $1800^{\circ} \mathrm{C}$ & 0.2217 & 402 & 308 & $0.77 \pm 0.07$ & 707 & $9.32 \pm 0.22$ & $0.036 \pm 0.004$ & 568 \\
\hline $\mathrm{SK} 1 \mathrm{~b} 900^{\circ} \mathrm{C}$ & 0.3789 & 275 & 332 & $1.21 \pm 0.20$ & 1296 & $8.96 \pm 0.05$ & $0.035 \pm 0.002$ & 212 \\
\hline SK $1 \mathrm{~b} 1800^{\circ} \mathrm{C}$ & 0.3789 & 7 & 12 & $1.73 \pm 0.57$ & 32 & $10.2 \pm 0.6$ & $0.039 \pm 0.011$ & 222 \\
\hline Total & 0.3789 & 282 & 345 & $1.22 \pm 0.22$ & 1328 & $8.99 \pm 0.11$ & $0.036 \pm 0.003$ & 212 \\
\hline SK $3600^{\circ} \mathrm{C}$ & 0.3155 & 24 & 25 & $1.06 \pm 0.25$ & 1599 & $9.29 \pm 0.17$ & $0.030 \pm 0.004$ & 15 \\
\hline SK3 $900^{\circ} \mathrm{C}$ & 0.3155 & 108 & 54 & $0.50 \pm 0.10$ & 378 & $9.19 \pm 0.22$ & $0.032 \pm 0.003$ & 286 \\
\hline SK3 $1200^{\circ} \mathrm{C}$ & 0.3155 & 7 & 7 & $0.99 \pm 0.85$ & 8 & $11.2 \pm 1.5$ & $0.052 \pm 0.020$ & 811 \\
\hline SK3 $1500^{\circ} \mathrm{C}$ & 0.3155 & n.d. & n.d. & n.d. & 13 & $9.13 \pm 1.38$ & $0.026 \pm 0.016$ & n.d. \\
\hline $\mathrm{SK} 31800^{\circ} \mathrm{C}$ & 0.3155 & n.d. & n.d. & n.d. & 24 & $9.86 \pm 0.76$ & $0.030 \pm 0.011$ & n.d. \\
\hline Total & 0.3155 & 139 & 86 & $0.62 \pm 0.28$ & 2023 & $9.28 \pm 0.25$ & $0.031 \pm 0.004$ & 69 \\
\hline $\mathrm{SK} 41000^{\circ} \mathrm{C}$ & 0.5542 & 11.7 & 7.1 & $0.61 \pm 0.26$ & 4.18 & $11.6 \pm 1.6$ & $0.091 \pm 0.021$ & 2805 \\
\hline $\mathrm{SK} 41100^{\circ} \mathrm{C}$ & 0.5542 & 5.2 & 7.2 & $1.38 \pm 0.52$ & 7.89 & $12.5 \pm 0.8$ & $0.095 \pm 0.009$ & 660 \\
\hline $\mathrm{SK} 41200^{\circ} \mathrm{C}$ & 0.5542 & 0.51 & n.d. & n.d. & 6.91 & $12.7 \pm 1.5$ & $0.039 \pm 0.010$ & 73 \\
\hline $\mathrm{SK} 41300^{\circ} \mathrm{C}$ & 0.5542 & 0.33 & n.d. & n.d. & 1.94 & $15.3 \pm 2.9$ & $0.145 \pm 0.043$ & 171 \\
\hline SK4 $1400^{\circ} \mathrm{C}$ & 0.5542 & 0.77 & n.d. & n.d. & 1.39 & $9.6 \pm 4.5$ & $0.024 \pm 0.042$ & 550 \\
\hline SK4 $1600^{\circ} \mathrm{C}$ & 0.5542 & 0.03 & n.d. & n.d. & 5.97 & $9.6 \pm 2.4$ & $0.023 \pm 0.019$ & n.d. \\
\hline $\mathrm{SK} 41800^{\circ} \mathrm{C}$ & 0.5542 & n.d. & n.d. & n.d. & 3.40 & $9.4 \pm 3.9$ & $0.030 \pm 0.034$ & n.d. \\
\hline Total & 0.5542 & 18.6 & $>14.3$ & $0.85 \pm 0.411$ & 32 & $11.6 \pm 2.3$ & $0.062 \pm 0.022$ & 586 \\
\hline
\end{tabular}

Calculated from $1000^{\circ} \mathrm{C}$ and $1100^{\circ} \mathrm{C}$ fractions.

gases and a standard helium gas with ${ }^{3} \mathrm{He} /{ }^{4} \mathrm{He}=1.71 \times$ $10^{-4}$ prepared by mixing pure ${ }^{3} \mathrm{He}$ and ${ }^{4} \mathrm{He}$ gases at our laboratory. The mass interference of ${ }^{40} \mathrm{Ar}^{++}$and $\mathrm{CO}_{2}{ }^{++}$in the neon analysis was corrected using experimentally determined ${ }^{40} \mathrm{Ar}^{++} / 40 \mathrm{Ar}^{+}$and $\mathrm{CO}_{2}{ }^{++} / \mathrm{CO}_{2}{ }^{+}$ratios (Osawa, 2004). For the $\mathrm{Ne}$ analysis, the argon and carbon dioxide were removed using a liquid-nitrogen-cooled trap beside a source of ions. The background was determined by heating an empty Mo crucible. The background levels of ${ }^{4} \mathrm{He}$, ${ }^{20} \mathrm{Ne},{ }^{40} \mathrm{Ar},{ }^{84} \mathrm{Kr}$, and ${ }^{132} \mathrm{Xe}$ at $1800^{\circ} \mathrm{C}$ were $9.89 \times 10^{-10}$ $\mathrm{cm}^{3}$ STP, $2.91 \times 10^{-12} \mathrm{~cm}^{3}$ STP, $7.21 \times 10^{-10} \mathrm{~cm}^{3} \mathrm{STP}, 5.46$ $\times 10^{-14} \mathrm{~cm}^{3} \mathrm{STP}$, and $1.19 \times 10^{-15} \mathrm{~cm}^{3} \mathrm{STP}$, respectively.

\section{Neutron activation analysis}

Iridium concentration can be determined using Instrumental Neutron Activation Analysis (INAA) with the multiple gamma-ray detection method. The nuclide quantification method was developed by Oshima et al. (Toh et al., 2001; Hatsukawa et al., 2002; Oshima et al., 2002, 2008) and has been successfully applied in a variety of fields. The iridium in the geological samples was determined using the multi-parameter coincidence method with no chemical separation after neutron irradiation. Fifty to one hundred $\mathrm{mg}$ of ground homogenized fish clay sediment samples were sealed in pure quartz vials and then irradiated for 48 hours in the JRR-3 reactor at JAEA with a neutron flux of $9.6 \times 10^{13} \mathrm{ncm}^{-2} \mathrm{~s}^{-1} .100 \mathrm{ng}$ standard iridium samples made from diluted Ir standard solution (ACROS Organic Co.) were also prepared, sealed in quartz vials, and then irradiated together with the sediment samples. After irradiation, the samples were cooled for about four weeks. The gamma ray decay was measured using GEMINI-II, an array of 16 high purity Ge detectors, with a typical measurement taking about a day. The $\gamma-\gamma$ coincidence peak of $468-316 \mathrm{keV}$ from ${ }^{192} \mathrm{Ir}$ $\left(T_{1 / 2}=73.8 \mathrm{~d}\right)$ produced by the ${ }^{191} \operatorname{Ir}(n, \gamma){ }^{192} \operatorname{Ir}$ reaction was used in quantitative analysis. All the samples were measured with a standard ${ }^{133} \mathrm{Ba}$ source to perform dead-time calibration of the detector system. The iridium content of the sediment samples was obtained by comparing the ${ }^{192} \mathrm{Ir}$ intensity of the sediment samples with the standard iridium after decay time corrections.

\section{RESULTS}

\section{Ir concentration}

The measured Ir concentrations of the 8 samples are listed in Table 1. The one-sigma errors are lower than $6 \%$. Anomalously high concentrations over $10 \mathrm{ppb}$ are detected in 5 of the samples. The highest concentration, $29.9 \mathrm{ppb}$, is found in SK7, which is consistent with the previously reported values of 31.0 and $36.0 \mathrm{ppb}$ in bed II or III (Kyte et al., 1980). The Ir concentrations of the four samples for which noble gas analysis was carried 
Table 3. Concentration and isotopic ratio of heavy noble gases

\begin{tabular}{|c|c|c|c|c|c|c|c|c|c|}
\hline Sample & $\begin{array}{l}\text { Weight } \\
(\mathrm{g})\end{array}$ & $\begin{array}{c}{ }^{40} \mathrm{Ar} \\
\left(10^{-9} \mathrm{~cm}^{3} \mathrm{STP} / \mathrm{g}\right)\end{array}$ & $\begin{array}{c}{ }^{36} \mathrm{Ar} \\
\left(10^{-9} \mathrm{~cm}^{3} \mathrm{STP} / \mathrm{g}\right)\end{array}$ & ${ }^{40} \mathrm{Ar} /{ }^{36} \mathrm{Ar}$ & ${ }^{38} \mathrm{Ar} /{ }^{36} \mathrm{Ar}$ & $\begin{array}{c}{ }^{84} \mathrm{Kr} \\
\left(10^{-12} \mathrm{~cm}^{3} \mathrm{STP} / \mathrm{g}\right)\end{array}$ & $\begin{array}{c}{ }^{132} \mathrm{Xe} \\
\left(10^{-12} \mathrm{~cm}^{3} \mathrm{STP} / \mathrm{g}\right)\end{array}$ & ${ }^{36} \mathrm{Ar} /{ }^{132} \mathrm{Xe}$ & ${ }^{84} \mathrm{Kr} /{ }^{132} \mathrm{Xe}$ \\
\hline SK1a & 0.2217 & 2,544 & 3.192 & $797 \pm 9$ & $0.1896 \pm 0.0003$ & 296 & 86 & 37 & 3.5 \\
\hline SK $1 \mathrm{~b} 900^{\circ} \mathrm{C}$ & 0.3789 & 99,012 & 319 & $310 \pm 2$ & $0.1898 \pm 0.0017$ & 13,470 & 1,311 & 243 & 10.3 \\
\hline $\mathrm{SK} 1 \mathrm{~b} 1800^{\circ} \mathrm{C}$ & 0.3789 & 529 & 0.14 & $3742 \pm 20$ & $0.1909 \pm 0.0012$ & 5.3 & 0.49 & 291 & 10.9 \\
\hline Total & & 99,542 & 319 & $312 \pm 2$ & $0.1898 \pm 0.0017$ & 13,475 & 1,312 & 243 & 10.3 \\
\hline $\mathrm{SK} 3600^{\circ} \mathrm{C}$ & 0.3155 & 383 & 0.289 & $1322 \pm 1$ & $0.1900 \pm 0.0011$ & 7.12 & 0.33 & 872 & 21.4 \\
\hline SK $3900^{\circ} \mathrm{C}$ & 0.3155 & 1,521 & 4.749 & $320 \pm 1$ & $0.1890 \pm 0.0017$ & 41.3 & 3.65 & 1300 & 11.3 \\
\hline SK3 $1200^{\circ} \mathrm{C}$ & 0.3155 & 139 & 0.046 & $3017 \pm 19$ & $0.1910 \pm 0.0019$ & 2.42 & 0.28 & 166 & 8.7 \\
\hline SK3 $1500^{\circ} \mathrm{C}$ & 0.3155 & 11 & 0.024 & $471 \pm 4$ & $0.1864 \pm 0.0022$ & 0.44 & 0.04 & 573 & 10.7 \\
\hline $\mathrm{SK} 31800^{\circ} \mathrm{C}$ & 0.3155 & 10 & 0.033 & $296 \pm 2$ & $0.1881 \pm 0.0023$ & 0.90 & 0.06 & 554 & 14.9 \\
\hline Total & & 2,064 & 5.141 & $401 \pm 2$ & $0.1890 \pm 0.0017$ & 52.2 & 4.37 & 1178 & 11.9 \\
\hline $\mathrm{SK} 41000^{\circ} \mathrm{C}$ & 0.5542 & 76 & 0.011 & $7184 \pm 175$ & $0.1920 \pm 0.0037$ & 0.55 & 0.04 & 286 & 14.9 \\
\hline $\mathrm{SK} 41100^{\circ} \mathrm{C}$ & 0.5542 & 296 & 0.032 & $9163 \pm 294$ & $0.1911 \pm 0.0017$ & 1.63 & 0.15 & 221 & 11.1 \\
\hline $\mathrm{SK} 41200^{\circ} \mathrm{C}$ & 0.5542 & 197 & 0.028 & $7082 \pm 179$ & $0.1911 \pm 0.0022$ & 2.14 & 0.20 & 139 & 10.7 \\
\hline $\mathrm{SK} 41300^{\circ} \mathrm{C}$ & 0.5542 & 22 & 0.013 & $1596 \pm 4$ & $0.1926 \pm 0.0025$ & 0.19 & 0.01 & 966 & 13.6 \\
\hline $\mathrm{SK} 41400^{\circ} \mathrm{C}$ & 0.5542 & 11 & 0.010 & $1091 \pm 5$ & $0.1918 \pm 0.0029$ & 0.10 & 0.01 & 1039 & 10.2 \\
\hline $\mathrm{SK} 41600^{\circ} \mathrm{C}$ & 0.5542 & 7 & 0.008 & $867 \pm 11$ & $0.1883 \pm 0.0036$ & 0.20 & 0.02 & 507 & 12.5 \\
\hline $\mathrm{SK} 41800^{\circ} \mathrm{C}$ & 0.5542 & 3 & 0.009 & $341 \pm 2$ & $0.1893 \pm 0.0039$ & 0.30 & 0.02 & 342 & 12.0 \\
\hline Total & & 612 & 0.111 & $5509 \pm 190$ & $0.1911 \pm 0.0026$ & 5.11 & 0.45 & 248 & 11.4 \\
\hline
\end{tabular}

out varied. SK3 and SK1b had the relatively low Ir concentrations of 2.5 and $4.6 \mathrm{ppb}$, respectively. On the other hand, SK1a and SK4 have anomalously high Ir concentrations of 24.7 and $14.3 \mathrm{ppb}$, respectively, leading to the conclusion that extraterrestrial material is present.

\section{Noble gas composition}

The measured noble gas concentrations and isotopic ratios of the four clay samples are summarized in Tables 2 and 3. The error is one sigma.

Helium ${ }^{3} \mathrm{He}$ is a very sensitive tracer of micrometeorites in sediments and is used to estimate the influx of micrometeorites onto the Earth (e.g., Farley, 1995; Mukhopadhyay et al., 2001). The extraterrestrial fraction of ${ }^{3} \mathrm{He}$ in the sediments can be calculated from ${ }^{3} \mathrm{He} /{ }^{4} \mathrm{He}$ ratio which is modeled as a simple two-component mixture of crustal and extraterrestrial He (Takayanagi and Ozima, 1987; Farley, 1995). ${ }^{4} \mathrm{He} /{ }^{20} \mathrm{Ne}$ ratios of the clay samples are more than 200 times the atmospheric ratio, 0.32 (Table 2), proving that the contribution of atmospheric ${ }^{3} \mathrm{He}$ is negligible. Assuming a ${ }^{3} \mathrm{He} /{ }^{4} \mathrm{He}$ ratio of 1.99 $\times 10^{-8}$ for clay (Andrews, 1985), the calculated extraterrestrial ${ }^{3} \mathrm{He}$ accounts for at least $96 \%$ of the total ${ }^{3} \mathrm{He}$.

It is notable that there is no correlation between Ir and ${ }^{3} \mathrm{He}$ concentration. The highest ${ }^{3} \mathrm{He}$ concentration of $3.45 \times 10^{-13} \mathrm{~cm}^{3} \mathrm{STP} / \mathrm{g}$ is found in SK1b, in which a low concentration of $\operatorname{Ir}(5.3 \mathrm{ppb})$ was detected. On the other hand, the lowest ${ }^{3} \mathrm{He}$ concentration of $>1.43 \times 10^{-14}$ $\mathrm{cm}^{3} \mathrm{STP} / \mathrm{g}$ is observed in SK1b, which has a high Ir concentration of $14.3 \mathrm{ppb}$. SK1a has the highest Ir concen- tration $(24.7 \mathrm{ppb})$ and high ${ }^{3} \mathrm{He}$ concentration $(3.08 \times$ $\left.10^{-13} \mathrm{~cm}^{3} \mathrm{STP} / \mathrm{g}\right)$. The discrepancy between $\mathrm{Ir}$ and ${ }^{3} \mathrm{He}$ concentration can be explained by positing that ${ }^{3} \mathrm{He}$ concentration is affected by two factors: nonuniformity of the small number of micrometeorites stored in the clays and high variation of the accumulation rate. Since there is no correlation between $\mathrm{Ir}$ and ${ }^{3} \mathrm{He}$ concentration, it is clear that most of the extraterrestrial ${ }^{3} \mathrm{He}$ in the $\mathrm{K}-\mathrm{T}$ boundary clays is not due to a bolide hitting the earth, and originates from micrometeorites accreted on the Earth.

Takaoka and Miura (1989) reported a definite excess of ${ }^{3} \mathrm{He}$ in a sample of Stevns Klint clay treated with $\mathrm{HCl} /$ HF. They found a ${ }^{3} \mathrm{He} /{ }^{4} \mathrm{He}$ ratio of $97 \pm 3 \times 10^{-6}$, which is 69 times the atmospheric value. However, no such high isotopic ratios are found in our samples, which is presumably because there was no separation of the samples. Neon The Ne isotopic compositions are plotted in Fig. 1. The Ne released from SK1a, SK1b and SK3 is predominantly atmospheric $\mathrm{Ne}$, their total $\mathrm{Ne}$ isotopic compositions corresponding to the results of Takaoka and Miura (1989), in which ${ }^{20} \mathrm{Ne} /{ }^{22} \mathrm{Ne}=9.43 \pm 0.08$ and ${ }^{21} \mathrm{Ne} /{ }^{22} \mathrm{Ne}$ $=0.0385 \pm 0.0065$. However, the Ne concentration of SK4 is much lower than the other samples and its isotopic composition is exceptional. Both the ${ }^{20} \mathrm{Ne} /{ }^{22} \mathrm{Ne}$ and ${ }^{21} \mathrm{Ne} /{ }^{22} \mathrm{Ne}$ ratios of SK4 are clearly higher than those of the atmosphere, revealing the presence of a non-atmospheric source.

The high ratio of ${ }^{20} \mathrm{Ne} /{ }^{22} \mathrm{Ne}$ can be explained by the contribution of the solar wind or mantle, but it is not easy to explain how mantle $\mathrm{Ne}$ can exist in marl. Micrometeorites are, therefore, a more plausible source 

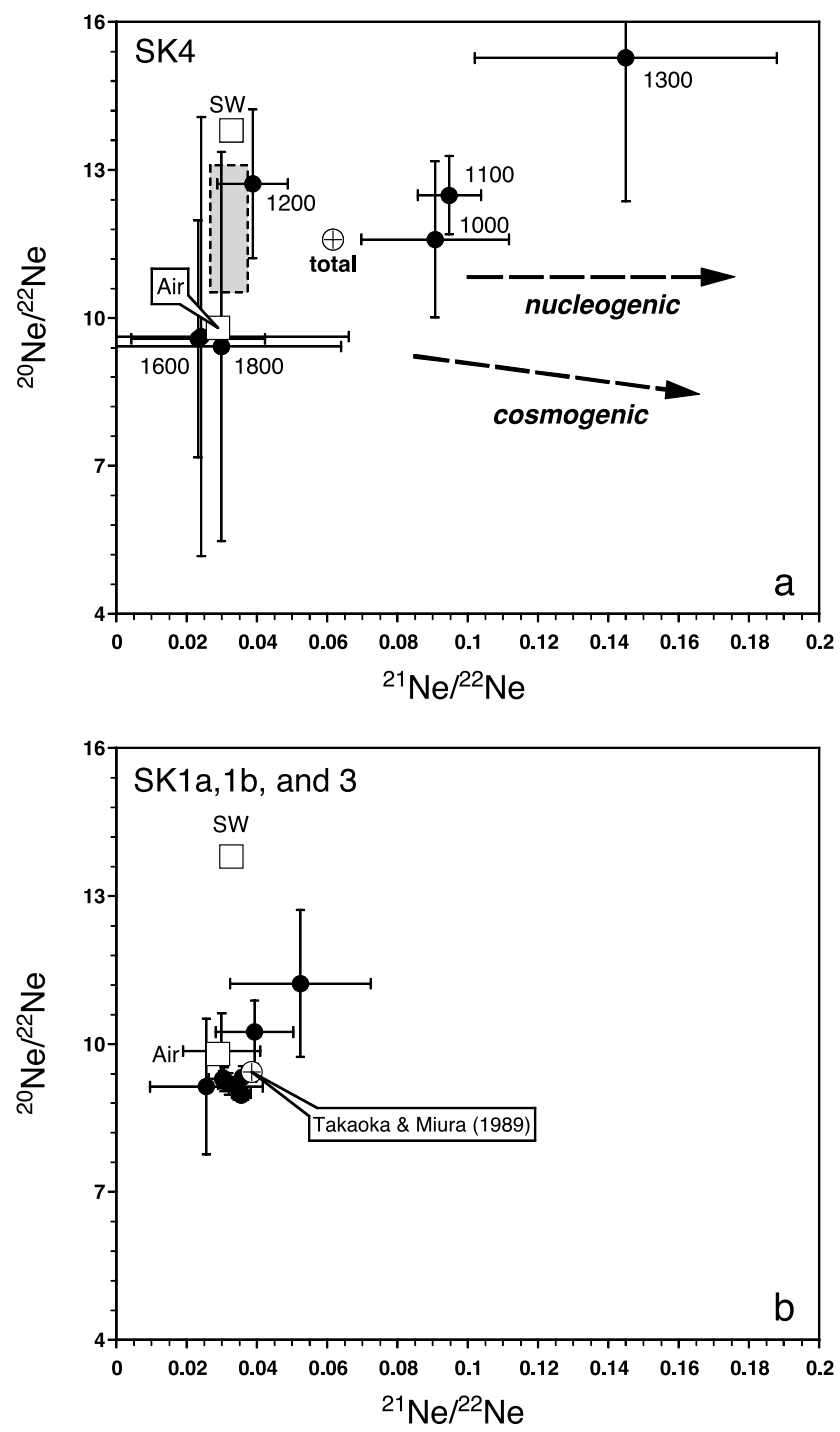

Fig. 1. Three isotope plot of Ne for SK4 (a) and others (b). The data from all temperature fractions is given. Solar wind $(S W)$ Ne after Benkert et al. (1993) and Air-Ne after Eberhardt et al. (1965). Errors are one sigma. The numbers shown in the upper diagram give the temperature in centigrade. The shaded area indicates the range of micrometeorites (e.g., Osawa et al., 2003). In the lower diagram Takaoka and Miura (1989) give the data from SK2-4R, an $\mathrm{HCl} / \mathrm{HF}$ treated residue.

of the solar-like Ne because micrometeorites retain large amounts of solar noble gases (e.g., Osawa and Nagao, 2002; Osawa et al., 2003) and it is known that solarderived $\mathrm{Ne}$ gets concentrated in deep-sea sediment (Matsuda et al., 1990). The high ratio of ${ }^{21} \mathrm{Ne} /{ }^{22} \mathrm{Ne}$ in SK4 is probably due to nucleogenic ${ }^{21} \mathrm{Ne}$ produced in the ${ }^{18} \mathrm{O}(\alpha, n){ }^{21} \mathrm{Ne}$ reaction, because cosmogenic ${ }^{21} \mathrm{Ne}$ is scarce in micrometeorites (e.g., Osawa and Nagao, 2002). Judging from the overall composition of the $\mathrm{Ne}$ in the sample

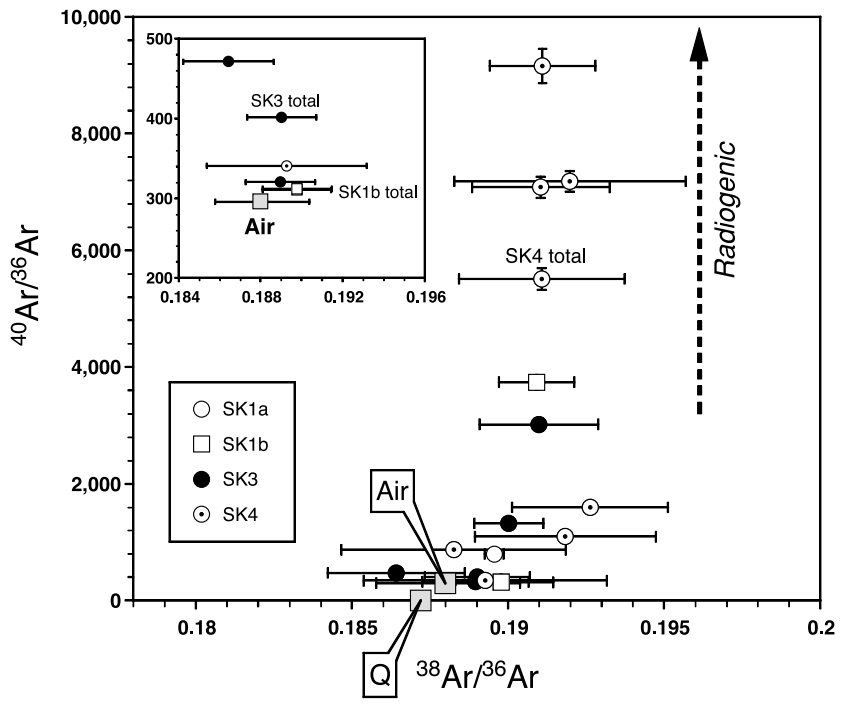

Fig. 2. Three isotope plot of Ar for all samples. Errors are one sigma. Q-Ar after Busemann et al. (2000) and Air-Ar after Nier (1950).

$\left({ }^{20} \mathrm{Ne} /{ }^{22} \mathrm{Ne}=11.6,{ }^{21} \mathrm{Ne} /{ }^{22} \mathrm{Ne}=0.062\right)$ the contribution of non-atmospheric $\mathrm{Ne}$ is high. This isotopic composition is also due to the low concentration of total $\mathrm{Ne}$, only $3.2 \times$ $10^{-11} \mathrm{~cm}^{3} \mathrm{STP} / \mathrm{g}$.

The isotopic composition of the Ne in SK1a is different from SK4, with no sign of solar-derived Ne, although the clay did have the highest Ir concentration of all the samples, thus revealing the presence of extraterrestrial material. The Ne trapped in SK1a is almost all terrestrial. Assuming that all ${ }^{3} \mathrm{He}$ is derived from micrometeorites and that the average ${ }^{3} \mathrm{He} /{ }^{20} \mathrm{Ne}$ ratio of micrometeorites is 0.0085 (Nakamura and Takaoka, 2000), the contribution of solar-Ne can be roughly estimated from the concentrations of ${ }^{3} \mathrm{He}$. The contributions of micrometeorite-derived ${ }^{20} \mathrm{Ne}$ in SK1a, SK1b, SK3 and SK4 are 5.1\%,3.1\%, $0.5 \%$ and $>5.3 \%$, respectively. The low value of $>5.3 \%$ in SK4 might indicate a preferential loss of ${ }^{3} \mathrm{He}$, although the mechanism is not clear.

Heavy noble gases Ar isotopic composition is the most sensitive indicator for extraterrestrial samples that have been heavily contaminated or degassed through heating or alteration. There are three reasons why Ar is a sensitive indicator for extraterrestrial material: 1) The sensitivity of the mass spectrometer to Ar is higher than to $\mathrm{He}$ or Ne. 2) Mass interferences of ${ }^{36} \mathrm{Ar},{ }^{38} \mathrm{Ar},{ }^{40} \mathrm{Ar}$ are not serious in a mass spectrometer with mass resolution of 600. 3) The shift of the ${ }^{40} \mathrm{Ar} /{ }^{36} \mathrm{Ar}$ ratio is very large, because most ${ }^{40} \mathrm{Ar}$ is produced from the electron-capture radioactive decay of ${ }^{40} \mathrm{~K}$. Osawa and Nagao (2003) revealed that about $40 \%$ of totally melted spherules contain extraterrestrial Ar because the Ar is well preserved compared to $\mathrm{He}$ and $\mathrm{Ne}$. 


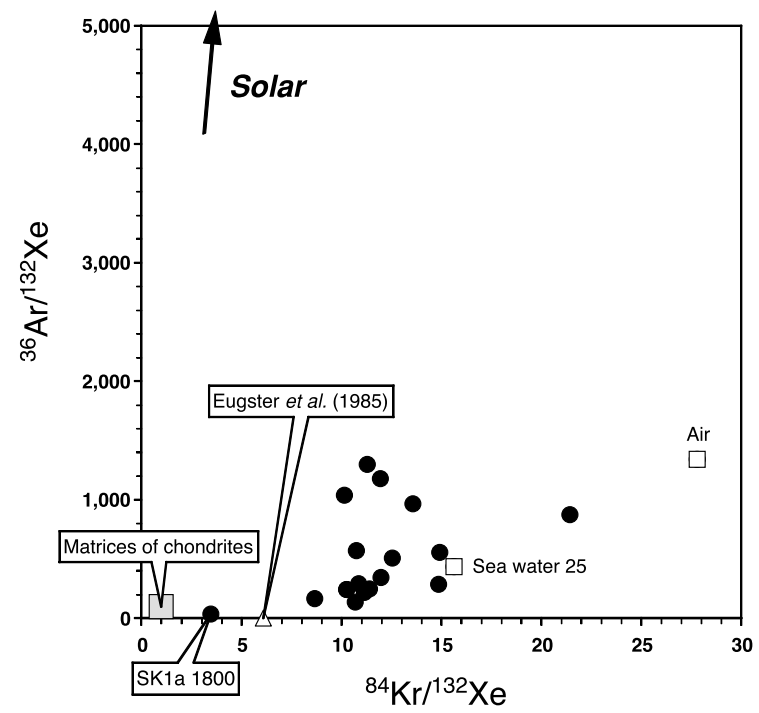

Fig. 3. Heavy noble gas elemental compositions for all fractions. Eugster et al. (1985) give the total amount of noble gases released from Stevns Klint 2 residue (run2) that had been treated with $\mathrm{HCl} / \mathrm{HF}$. Heavily fractionated terrestrial atmosphere is found in SKIa. Saturated noble gases in sea water at $25^{\circ} \mathrm{C}$ as calculated by Ozima and Podosek (2002).

Since ${ }^{40} \mathrm{Ar}$ in primordial $\mathrm{Ar}$ in the solar system is scarce, the ${ }^{40} \mathrm{Ar} /{ }^{36} \mathrm{Ar}$ ratio can provide important information on extraterrestrial materials when the radiogenic ${ }^{40} \mathrm{Ar}$ and atmospheric contamination are not exceptionally large. A three isotope plot of the $\mathrm{K}-\mathrm{T}$ boundary clay is given in Fig. 2. No sample has a ${ }^{40} \mathrm{Ar} /{ }^{36} \mathrm{Ar}$ ratio lower than that of the terrestrial atmosphere, 296. SK1a and SK4, with their high Ir concentrations, have high ${ }^{40} \mathrm{Ar} /{ }^{36} \mathrm{Ar}$ ratios, reflecting the presence of radiogenic ${ }^{40} \mathrm{Ar}$ produced from in situ radioactive decay of ${ }^{40} \mathrm{~K}$. The Ar isotopic ratios of SK1b and SK3 are near that of the atmosphere. ${ }^{38} \mathrm{Ar} /{ }^{36} \mathrm{Ar}$ ratios higher than that of the atmosphere, 0.188 , are found in all the samples, presumably indicating the presence of nucleogenic ${ }^{38} \mathrm{Ar}$ originating from the ${ }^{35} \mathrm{Cl}(\alpha, p){ }^{38} \mathrm{Ar}$ reaction. As in the case of Eugster et al. (1985), there is no sign of extraterrestrial Ar isotopes in our samples.

The elemental compositions of $\mathrm{Ar}, \mathrm{Kr}$, and $\mathrm{Xe}$ are given in Fig. 3. All the samples have ${ }^{84} \mathrm{Kr} /{ }^{132} \mathrm{Xe}$ and ${ }^{36} \mathrm{Ar} /$ ${ }^{132} \mathrm{Xe}$ ratios lower than that of the terrestrial atmosphere, SK1a in particular being near the region of chondrite matrices. However, elemental compositions do not demonstrate the presence of extraterrestrial noble gases because adsorbed gases get heavily fractionated (Scherer $e t$ al., 1994). Eugster et al. (1985) also reported low ${ }^{84} \mathrm{Kr} /$ ${ }^{132} \mathrm{Xe}$ and ${ }^{36} \mathrm{Ar} /{ }^{132} \mathrm{Xe}$ ratios. SK $1 \mathrm{~b}$ contains vary large amounts of $\mathrm{Ar}, \mathrm{Kr}$, and $\mathrm{Xe}$ compared to the other samples (Table 3) and its ${ }^{40} \mathrm{Ar} /{ }^{36} \mathrm{Ar}$ ratio of $312 \pm 2$ is close to that of terrestrial atmosphere, indicating that the high concentrations of heavy noble gases are mainly due to adsorbed air. However, the elemental composition of the clay is significantly fractionated $\left({ }^{36} \mathrm{Ar} /{ }^{132} \mathrm{Xe}=243,{ }^{84} \mathrm{Kr} /{ }^{132} \mathrm{Xe}\right.$ $=10.3)$. The cause of the exceptionally high concentrations of heavy noble gases in SK1b may be large surface area due to the grain size.

The Xe isotopic compositions, which are not specifically analyzed here, are closer to the terrestrial atmosphere than any other extraterrestrial source.

\section{DiscuSsION}

There is no evidence of extraterrestrial Ar, $\mathrm{Kr}$, or Xe. However, the Ne in SK4 clearly indicates the presence of solar-derived $\mathrm{Ne}$, which presumably originated in micrometeorites. In fact, when the nucleogenic (or cosmogenic) $\mathrm{Ne}$ is subtracted from the overall $\mathrm{Ne}$, the corrected $\mathrm{Ne}$ composition corresponds to that of micrometeorites (Fig. 1).

It is, however, very difficult to accept that a bolide hitting the earth would include a lot of solar-derived $\mathrm{Ne}$, because solar winds can only penetrate several hundred angstroms into the surface of rock (Benkert et al., 1993). Further, since the diameter of the asteroid has been estimated to be $10 \pm 4$ kilometers (Alvarez et al., 1980) the amount of solar-Ne is negligible. The solar-derived $\mathrm{Ne}$ therefore seems to be unrelated to the asteroid itself.

If the source of the solar-derived $\mathrm{Ne}$ is micrometeorites, can it then be said that a flux of extraterrestrial dust rose at the $\mathrm{K}-\mathrm{T}$ boundary? Mukhopadhyay et al. (2001) measured the He concentration in marine carbonates throughout a time span of 63.9 to 65.4 million years ago and concluded that the bolide associated with the $\mathrm{K}-\mathrm{T}$ extinction event was not accompanied by enhanced solar system dustiness, due to the near-constant ${ }^{3} \mathrm{He}$ accretion rate across the boundary. The detected solar-like Ne might be merely due to low interference of atmospheric $\mathrm{Ne}$.

The ${ }^{3} \mathrm{He} /{ }^{20} \mathrm{Ne}$ ratio of SK4, 0.00045 , is significantly lower than that of average micrometeorites, 0.0085 (Nakamura and Takaoka, 2000), and the noble gas concentrations of SK4 are much lower than those of other samples. The result may reflect noble gas depletion by heating. In a stepwise heating experiment performed on micrometeorite-bearing particles separated from Antarctic ice, about $87 \%$ of $\mathrm{He}$ was extracted at $700^{\circ} \mathrm{C}$ but about $71 \%$ of Ne still remained (Nakamura and Takaoka, 2000). Indeed, severely heated extraterrestrial particles, such as cosmic spherules, have a low $\mathrm{He} / \mathrm{Ne}$ ratio (Osawa and Nagao, 2003). In the age when SK4 cumulated, severely heated extraterrestrial particles, e.g., particles with very fast relative speed to the Earth, might have been predominant, and the event might be linked with some kind of 
astronomical phenomenon.

Our results also show that noble gases trapped in the $\mathrm{K}-\mathrm{T}$ extraterrestrial projectile had been mostly depleted. If the Ir concentration of the projectile is assumed to have been $470 \mathrm{ppb}$, which is a typical concentration in CI chondrite and reflects the solar abundance, the extraterrestrial material in SK1a was diluted to $1 / 19$. Further, if the ${ }^{36} \mathrm{Ar}$ concentration of the projectile is assumed to have been $8.0 \times 10^{-7} \mathrm{~cm}^{3} \mathrm{STP} / \mathrm{g}$, which is the average concentration in CI chondrite, the ${ }^{36} \mathrm{Ar}$ concentration in SK1a should be $4.2 \times 10^{-8} \mathrm{~cm}^{3} \mathrm{STP} / \mathrm{g}$, thirteen times higher than the ${ }^{36} \mathrm{Ar}$ concentration in SK1a found in this study. In SK4, only $0.45 \%$ of the extraterrestrial ${ }^{36} \mathrm{Ar}$ is estimated to have remained in the clay. This indicates that there was a rise in temperature to over $1000^{\circ} \mathrm{C}$, which explains why the noble gases almost completely escaped from the noble gas carriers of the bolide even though the primordial noble gas component trapped in the chondrite was tightly captured.

Although a highly sensitive mass spectrometer was used, no sign of chondritic noble gases was found in this study. Even if the sensitivity of mass spectrometers is greatly improved in the future, it will still be difficult to identify the noble gases associated with the projectile without the analysis of a large amount of the $\mathrm{K}-\mathrm{T}$ boundary clay.

\section{CONCLUSION}

The Ir concentrations of eight $\mathrm{K}-\mathrm{T}$ boundary samples collected from Stevns Klint were measured, and four of them were subjected to noble gas analysis. Five of the samples had Ir anomalies, with the highest value being $29.9 \mathrm{ppb}$, which is consistent with previously reported concentrations. As in the case of previous noble gas research conducted on $\mathrm{K}-\mathrm{T}$ boundary clay, there was no sign of extraterrestrial $\mathrm{Ar}, \mathrm{Kr}$, and $\mathrm{Xe}$ isotopic and elemental compositions in the Stevns Klint samples. The compositions of these three elements can be explained as being due to the contribution of adsorbed terrestrial atmosphere, radiogenic nuclides, and nucleogenic nuclides. On the other hand, most of the ${ }^{3} \mathrm{He}$ is extraterrestrial and can be traced to micrometeorites. Solar-like Ne was observed in SK4, in which the relatively high Ir concentration of $14.3 \mathrm{ppb}$ was detected through multiple gammaray analysis. The source of the solar-like $\mathrm{Ne}$ was presumed to be micrometeorites accreted on the earth, because micrometeorites preserve solar noble gases. That said, though the projectile associated with the $\mathrm{K}-\mathrm{T}$ extinction was massive, the amount of solar-derived $\mathrm{Ne}$ it contained was negligible when compared with the overall amount of Ne. Further, no evidence of a dramatic increase in the accretion rate of extraterrestrial dust was discovered. It is, therefore, still unclear whether the solar-like $\mathrm{Ne}$ is re- lated to the mass extinction event that led to the extinction of so many living things.

Acknowledgments-Des Patterson and an anonymous referee are thanked for their constructive comments and suggestions.

\section{REFERENCES}

Alvarez, L. W., Alvarez, W., Asaro, F. and Michel, H. V. (1980) Extraterretsrial cause for the Cretaceous-Tertiary extinction. Science 208, 1095-1108.

Amari, S., Ozima, M. and Hamano, Y. (1988) The ${ }^{3} \mathrm{He} /{ }^{4} \mathrm{He}$ ratio in a clay from the K-T boundary Hokaaido, Japan. Proc. NIPR Antarct. Meteorites 1, 310-314.

Andrews, J. N. (1985) The isotopic composition of radiogenic helium and its use to study groundwater movement in confined aquifers. Chem. Geol. 49, 339-351.

Benkert, J. P., Baur, H., Signer, P. and Wieler, R. (1993) He, $\mathrm{Ne}$, and Ar from the solar wind and solar energetic particles in lunar ilmenites and pyroxenes. J. Geophys. Res. 98, E7, 13147-13162.

Busemann, H., Baur, H. and Wieler, R. (2000) Primordial noble gases in "phase Q" in carbonaceous and ordinary chondrites studied by closed-system stepped etching. Meteorit. Planet. Sci. 35, 949-973.

Christensen, L., Fregerslev, S., Simonsen, A. and Thiede, J. (1973) Sedimentology and depositional environment of lower Danian fish clay from Stevns Klint, Denmark. Bull. Geol. Soc. Den. 22, 193-212.

Eberhardt, P., Eugster, O. and Marti, K. (1965) A redetermination of the isotopic composition of atmospheric neon. $Z$. Naturforsch. 20a, 623-624.

Eugster, O., Geiss, J. and Krähenbühl, U. (1985) Noble gas isotopic abundances and noble metal concentrations in sediments from the Cretaceous-Tertiary boundary. Earth Planet. Sci. Lett. 74, 27-34.

Farley, K. A. (1995) Cenozoic variations in the flux of interplanetary dust recorded by ${ }^{3} \mathrm{He}$ in a deep-sea sediment. Nature 376, 153-156.

Hatsukawa, Y., Oshima, M., Hayakawa, T., Toh, Y. and Shinohara, N. (2002) Application of multiparameter coincidence spectrometry using a Ge detectors array to neutron activation analysis. Nucl. Instrum, Methods Phys. Res. A 482, 328-333.

Kastner, M., Asaro, F., Michel, H. V., Alvarez, W. and Alvarez, L. W. (1984) The precursor of the Cretaceous-Tertiary boundary clays at Stevns Klint, Denmark, and DSDP Hole 465A. Science 226, 137-143.

Kyte, F. T., Zhou, Z. and Wasson, T. (1980) Siderophileenriched sediments from the Cretaceous-Tertiary boundary. Science 288, 651-656.

Lewis, R. S. and Wolbach, W. S. (1986) Search for noble gases at the K-T boundary. Meteoritics 21, 434-435.

Lewis, R. S., Srinivasan, B. and Anders, E. (1975) Host phase of a strange xenon component in Allende. Science 190, 1251-1262.

Marti, K. and Craig, H. (1987) Cosmic-ray-produced neon and helium in the summit lavas of Maui. Nature 325, 335-337. 
Matsuda, J., Murota, M. and Nagao, K. (1990) He and Ne isotopic studies on the extraterrestrial material in deep-sea sediments. J. Geophys. Res. 95, 7111-7117.

Mukhopadhyay, S., Farley, K. A. and Montanari, A. (2001) A short duration of the Cretaceous-Tertiary boundary event: evidence from extraterrestrial helium-3. Science 291, 19521955.

Nakamura, T. and Takaoka, N. (2000) Solar-wind derived light noble gases in micrometeorites collected at the Dome Fuji Station: Characterization by trapped pyrolysis. Antarct. Meteorite Res. 13, 311-321.

Nier, A. O. (1950) A redetermination of the relative abundances of the isotopes of carbon, nitrogen, oxygen, argon and potassium. Phys. Rev. 77, 789-793.

Osawa, T. (2004) A new correction technique for mass interferences by ${ }^{40} \mathrm{Ar}^{++}$and $\mathrm{CO}_{2}{ }^{++}$during isotope analysis of a small amount of Ne. J. mass spectrum. Soc. Jpn. 52, 230-232.

Osawa, T. and Nagao, K. (2002) Noble gas compositions of Antarctic micrometeorites collected at the Dome Fuji Station in 1996 and 1997. Meteorit. Planet. Sci. 37, 911-936.

Osawa, T. and Nagao, K. (2003) Remnant extraterrestrial noble gases in Antarctic cosmic spherules. Antarct. Meteorite Res. 16, 196-219.

Osawa, T., Nakamura, T. and Nagao, K. (2003) Noble gas isotopes and mineral assemblages of Antarctic micrometeorites collected at the meteorite ice field around the Yamato Mountains. Meteorit. Planet. Sci. 38, 1627-1640.

Oshima, M., Toh, Y., Hatsukawa, Y., Hayakawa, T. and Shinohara, N. (2002) A high-sensitivity and non-destructive trace element analysis based on multiple gamma-ray detection. J. Nucl. Sci. Technol. 39, 292-294.

Oshima, M., Toh, Y., Hatsukawa, Y., Koizumi, M., Kimura, A., Haraga, A., Ebihara, M. and Sushida, K. (2008) Multiple gamma-ray detection method and its application to nuclear chemistry. J. Radioanal. Nucl. Chem. 278, 257-262.

Ozima, M. and Podosek, F. A. (2002) Noble Gas Geochemistry Second Edition. Cambridge University Press, Cambridge, U.K.

Scherer, P., Schultz, L. and Loeken, T. (1994) Weathering and atmospheric noble gases in chondrites. Noble Gas Geochemistry and Cosmochemistry (Matsuda, J., ed.), 4353, Terra Scientific Publishing Company, Japan.

Sharpton, V. L., Dalrymple, G. B., Marín, L. E., Ryder, G., Schuraytz, B. C. and Urrutia-Fucugauchi, J. (1992) New links between the Chicxulub impact structure and the Cretaceous/Tertiary boundary. Nature 359, 819-821.

Takaoka, N. and Miura, Y. (1989) Noble gases in the K-T boundary clay from Stevns Klint, Denmark. Proc. NIPR Antarct. Meteorites 2, 344-350.

Takayanagi, M. and Ozima, M. (1987) Temporal variation of ${ }^{3} \mathrm{He} /{ }^{4} \mathrm{He}$ ratio recorded in deep-sea sediment cores. $J$. Geophys. Res. 92, 12531-12538.

Toh, Y., Oshima, M., Hatsukawa, Y., Hayakawa, T. and Shinohara, N. (2001) Comparison method for neutron activation analysis with $\gamma-\gamma$ matrix. J. Radioanal. Nucl. Chem. 250, 373-376.

Wolbach, W. S., Lewis, R. S. and Anders, E. (1985) Cretaceous extinctions: evidence for wildfires and search for meteoritic material. Science 230, 167-170. 